ANADOLU, J. of AARI

ISSN: $1300-0225$ (Print)

E-ISSN: 2667-6087 (Online)

2021, 31 (2): 245-251

DOI: $10.18615 /$ anadolu.1033619

\title{
Sinop ve Kastamonu Illerinden Seçilen Yerel Elma Genotiplerinin Bazı Meyve Özellikleri Üzerine Bir Ön Çalışma
}

\author{
İdris MACíT ${ }^{*}$ \\ Erol $A Y D I N^{2}$ \\ ${ }^{1,2}$ Karadeniz Tarımsal Araştırma Enstitüsü, SAMSUN/TURKEY \\ ${ }^{1}$ https://orcid.org/0000-0001-6506-0758 2 $\quad{ }^{2}$ https://orcid.org/0000-0002-2710-4075 \\ *Corresponding author (Sorumlu yazar): idris.macit@tarimorman.gov.tr \\ Received (Geliş tarihi): 05.10.2021Ａccepted (Kabul tarihi): 02.11.2021
}

\begin{abstract}
ÖZ: Bu çalışma 2015 yllında Sinop ili Erfelek ilçesi ve Kastamonu ili merkez ilçesinde yetiştirilen yerel elma genotiplerinin çiçeklenme ve hasat tarihleri ile bazı meyve özeliklerinin belirlenmesi amacı ile yürütülmüşürr. Çalışmada meyve ağırlığl, meyve boyu ve eni, şekil indeksi, meyve sap uzunluğu ve kalınlı̆̆l, suda çözünebilir kuru madde miktarl ve titre edilebilir asit miktarı incelenmiştir. Elma genotiplerinin hasat tarihi Temmuz-Ekim ayları arasında dă̆gllm göstermiştir. Incelenen elma genotiplerinde meyve ağırlıkları 59,3-220,8 g, meyve boyu 48,3-67,3 mm, meyve eni 50,4-85,0 mm, meyve sap uzunluğu 7,9-17,5 mm, meyve sap kalınlığ ise 1,7-3,7 mm, suda çözünebilir kuru madde miktarl \%12,0-16,20, titre edilebilir asit içeriği \%0,250,60, arasında değişim göstermiştir. Bu genotiplerden 9 adedinde periyodisite görülmemiștir.
\end{abstract}

Anahtar kelimeler: Seleksiyon, pomoloji, fenoloji, periyodisite.

\section{A Preliminary Study on Some Fruit Characteristics of Local Apple Genotypes Selected from Sinop and Kastamonu Provinces}

\begin{abstract}
This study was carried out to determine the flowering and harvest dates and some fruit characteristics of local apple genotypes grown in the Erfelek district of Sinop province and central district of Kastamonu province in 2015. Fruit weight, fruit length and diameter, shape index, fruit stem length and thickness, total soluble solid and titratable acid content were investigated pomologically. Harvest date of apple genotypes ranged from July to October. In the types evaluated, fruit weight, fruit length and fruit diameter were in the ranges of 59.3-220.8 g, 48.3-67.3 mm and 50.4-85.0 mm, respectively. Total soluble solids and titratable acidity varied from $12.0-16.20 \%$ and $0.25-0.60 \%$, respectively. Periodicity was not observed in nine of these genotypes.
\end{abstract}

Keywords: Selection, pomology, phenological periodicity.

\section{GíRiș}

Anadolu coğrafi ve ekolojik koşulları nedeniyle birçok meyve türünün anavatanı ve yetişme alanıdır (Kaya ve Balta, 2013). Dünyadaki otuz dört yoğun biyolojik çeşitlilik merkezinden üçü (Kafkasya, Akdeniz ve İran-Anadolu) Türkiye'de kesişmektedir (Çalışkan ve ark., 2017; Engin ve Mert, 2020; Karataş ve Şengül, 2020). Türkiye'nin biyolojik çeşitlilik zenginliği küresel anlamda önemini ortaya koymaktadır. Bu bağlamda, doğal seleksiyonlar sonucu biyotik, abiyotik stres koşullarına dayanıklı ve kalite özellikleri iyi yerel tiplerin ortaya çıkma şansı yüksektir. Bu bakımdan önemli olan türlerden biri de elmadır. Elma gen merkezleri arasında Kuzey Anadolu, Karadeniz kıyı bölümü ile İç ve Doğu Anadolu yaylaları 
arasındaki geçit bölgeleri yer almaktadır. Bununla birlikte, İç Anadolu Bölgesi'nde, sert hava akımlarına karşı muhafazalı olan nemli vadilerde, Ege Bölgesi'nde de genellikle, yüksekliği 600 m'den daha fazla olan lokasyonlarda elma yetiştiriciliği yapılabilmektedir. Güney Anadolu'da ise yetiştiricilik 1000-1200 m yükseklikteki lokasyonlarda mümkün olmaktadır. Ülkemizde geniş yayılıma sahip olan elma için en elverişli yetişme alanları gen merkezlerimize paralel olarak daha çok Kuzey Anadolu'da bulunmaktadır (Özbek, 1978).

Kuzey Anadolu'nun kışları 1lık, yazları çok sıcak olmayan, nemli kıyı bölgeleri yerel elma çeşitleri bakımından oldukça zengindir. Elma genotipleri içerisinde yetiştiriciler tarafından beğenilen özelliklere sahip olan genotipler aşıyla çoğaltılarak günümüze kadar mevcudiyetini korumuş olup, genetik kaynak olarak değer taşımaktadır. Öte yandan, Ülkemizin sahip olduğu bu yerel elma genotiplerinin olumsuz çevre şartlarına rağmen (abiyotik ve biyotik) varlığını koruması üstün özellikleri dolayısıyla çeşit olma potansiyellerinin de yüksek olduğuna işaret etmektedir. Nitekim Şehirali ve Özgen (1987), günümüzde verimli, fakat dar genetik tabanlı olan tescilli çeşitler başta çevresel baskılara (hastalık, zararlı, soğuk ve kurak vb.) dayanıklılık bakımından yetersiz olduklarını, bu nedenle 1slahçıların uzun süreli olarak kantitatif; kısa ya da orta süreli olarak da kalitatif karakterleri (hastalıklara dayanıklılık vb.) aktarmak için yeni bitki genetik kaynakları aradıklarını ifade etmişlerdir.

$\mathrm{Bu}$ nedenle, ülkemiz meyveciliğinde elmanın, üretim miktarı, ağaç sayısı ve ekonomik değeri bakımından önemli bir yeri olduğu göz önünde bulundurulduğunda, bu yerel çeşitler üzerinde yapılan çalışmalar daha da değerli olmaktadır. Bu konuda literatürde Karadeniz Bölgesi'nin farklı il ve ilçelerinde bazı yerel elma genotiplerinin meyve özelliklerini inceleme amacıyla gerçekleştirilmiş araştırmalar bulunmaktadır (Serdar ve ark., 2007; Aygün ve Ülgen 2009; Bostan 2009; Bostan ve Acar 2009; Yarılgaç ve ark., 2009; İslam ve ark.,
2009; Kaplan ve Macit, 2009; Gürel 2010; Dumanoğlu ve ark., 2011; Karadeniz ve ark., 2013; Kirkaya ve ark., 2014; Bostan ve Y1lmaz 2015; Balta ve ark., 2015; Uzun ve ark., 2015; Karakaya ve ark., 2015, Macit ve ark., 2021).

Söz konusu çalışma; Sinop ili Erfelek ilçesi ve Kastamonu ili Merkez ilçesinde yetiştiriciliği çok eskilere dayanan elma türü içerisinde günümüze kadar gelebilmiş ve hala yetiştirilebilen elma genotiplerinin meyve ağırlığı, meyve eni ve boyu, Suda Çözünebilir Kuru Madde Miktarı (SÇKM), asitlik, meyve sap uzunluğu ve kalınlığ özelliklerini belirlemek amacıyla yapılmıştır. Yapılan çalışma belirlenen elma genotipleri korunarak ileride yapılacak çalışmalara kaynak oluşturmasına imkân tanıyabilecektir.

\section{MATERYAL ve METOT}

Çalışma 2015 yılında Sinop ili Erfelek ve Kastamonu ili Merkez ilçesinde yürütülmüştür. Sinop ili Erfelek ilçesi ve Kastamonu ili Merkez ilçesi 2015 yılı ve uzun y1llar ortalaması iklim verileri Çizelge 1 ve 2'de verilmiştir. Orta Karadeniz Bölgesinde yer alan Sinop ili Erfelek ilçesinde uzun yıllar ortalamasına göre ortalama yağış miktarı $72,75 \mathrm{~mm}$, nispi nem $\% 79,83$ ve ortalama sıcaklık ise $13,48{ }^{\circ} \mathrm{C}$ 'dir. 2015 yılında ise ortalama yağış miktarı uzun yıllar ortalamasının üzerinde gerçekleşirken, ortalama sıcaklık ise uzun yıllar ortalamasının altında gerçekleşmiştir. Batı Karadeniz Bölgesinde yer alan Kastamonu ili Merkez ilçesinde uzun yıllar ortalamasına göre ortalama yağış miktarı $43,77 \mathrm{~mm}$, nispi nem \% 70,62 ve ortalama sicaklik ise $10,05 \mathrm{C}^{0}$ dir. 2015 yılında ise sıcaklık, yağış ve nispi nem miktarı uzun yıllar ortalamasının üzerinde gerçekleşmiştir.

Farklı özellikleri ile öne çıkan Sinop ili Erfelek ilçesinden 8 adet, Kastamonu merkez ilçesinden de 6 adet olmak üzere toplam 14 yerel elma genotipi materyal olarak kullanılmıştır. Bu genotipler çögür anaç üzerine aşılı olarak yetiştirilmektedir. Genotiplere ait yerel isimler, lokasyon bilgileri (il, ilçe, köy, rakım), ağaç yaşı, çiçeklenme ve hasat 
tarihleri ile periyodisite durumları tespit edilmiştir. Genotipin yerel ismi, çiçeklenme ve hasat tarihi, periyodisite durumu üreticilerle kişisel görüşmeler sonucu tespit edilmiştir. Meyve özellikleri analizleri için her genotipten rastgele alınan 30 adet meyve kullanılarak ortalama meyve ağırlı̆̆ $(0,01$ g'ye hassas terazi ile), meyve boyu $(\mathrm{mm})$ ve eni $(\mathrm{mm})$, meyve şekil indeksi (meyve boyu/meyve eni) meyve sap uzunluğu ve kalınlığ $(0.01 \mathrm{~mm}$ hassas kumpas ile) belirlenmiştir. SÇKM el refraktometresi ile tespit edilmiştir. Titre edilebilir asitlik (TEA) için titrasyon metodu ile tespit edilmiştir. Elma genotiplerinin belirlenen meyve özellikleri ortalamaları ve standart hatalarıyla birlikte verilmiștir.

Çizelge 1. Sinop ili Erfelek ilçesinin iklim özellikleri.

Table 1. Climatic characteristics of the Erfelek district of Sinop.

\begin{tabular}{|c|c|c|c|c|c|c|c|c|}
\hline \multirow[b]{2}{*}{$\begin{array}{l}\text { Aylar } \\
\text { Months }\end{array}$} & \multicolumn{4}{|c|}{$\begin{array}{l}\text { Sicaklık }\left({ }^{\circ} \mathrm{C}\right) \\
\text { Temperature }\end{array}$} & \multicolumn{2}{|c|}{$\begin{array}{r}\text { Nispi nem (\%) } \\
\text { Relative humidity }\end{array}$} & \multicolumn{2}{|c|}{$\begin{array}{c}\text { Toplam Yağış }\left(\mathrm{mm}=\mathrm{kg} / \mathrm{m}^{2}\right) \\
\text { Total rainfall }\end{array}$} \\
\hline & $\begin{array}{l}2015 \\
\text { Min. }\end{array}$ & $\begin{array}{l}2015 \\
\text { Max. }\end{array}$ & $\begin{array}{c}2015 \\
\text { ort. } \\
\text { Ave. }\end{array}$ & $\begin{array}{l}\text { Uzun yillar } \\
\text { ort. } \\
\text { Long years } \\
\text { ave. }\end{array}$ & 2015 & $\begin{array}{l}\text { Uzun } \\
\text { y1llar ort. } \\
\text { Long } \\
\text { years } \\
\text { ave. }\end{array}$ & 2015 & $\begin{array}{l}\text { Uzun y1llar } \\
\text { ort. } \\
\text { Long years } \\
\text { ave. }\end{array}$ \\
\hline Ocak & $-10,0$ & 22,4 & 4,7 & 5,0 & 75,6 & 81,1 & 121,7 & 114,85 \\
\hline Şubat & $-7,1$ & 21,1 & 5,8 & 6,5 & 74,7 & 79,9 & 162,9 & 69,99 \\
\hline Mart & $-1,9$ & 24,4 & 7,1 & 8,4 & 78,8 & 77,8 & 49,5 & 77,19 \\
\hline Nisan & $-0,8$ & 26,1 & 9,5 & 11,1 & 68,3 & 75,7 & 56,0 & 43,38 \\
\hline Mayıs & 5,8 & 29,6 & 15,5 & 16,0 & 74,9 & 80,6 & 30,0 & 55,47 \\
\hline Haziran & 10,1 & 28,1 & 19,0 & 20,3 & 78,1 & 78,1 & 119,8 & 55,96 \\
\hline Temmuz & 12,4 & 32,3 & 21,5 & 22,1 & 71,1 & 76,1 & 7,6 & 35,58 \\
\hline Ağustos & 13,8 & 31,5 & 22,8 & 22,6 & 72,0 & 76,5 & 49,9 & 54,56 \\
\hline Eylül & 12,1 & 33,3 & 20,7 & 18,9 & 75,3 & 81,6 & 51,1 & 70,91 \\
\hline Ekim & 4,5 & 26,2 & 14,5 & 14,4 & 85,8 & 86,5 & 132,8 & 88,09 \\
\hline Kasım & 1,4 & 24,5 & 11,1 & 10,2 & 74,2 & 82,8 & 63,0 & 83,13 \\
\hline Aralık & $-4,0$ & 15,5 & 5,1 & 6,3 & 79,3 & 81,2 & 162,3 & 123,86 \\
\hline Ortalama & & & 13,11 & 13,48 & 75,68 & 79,83 & 83,88 & 72,75 \\
\hline
\end{tabular}

Kaynak: Meteorolojik veri arșiv ve yönetim sistemi. Meteoroloji 10. Bölge Müdürlüğü Erfelek/18136 no'lu istasyonu. Source: Meteorological data archive and management system. $10^{\text {th }}$ Regional Directorate of Meteorology Erfelek/18136 station.

Çizelge 2. Kastamonu ili Merkez ilçesinin iklim özellikleri.

Table 2. Climatic characteristics of the central district of Kastamonu.

\begin{tabular}{|c|c|c|c|c|c|c|c|c|}
\hline \multirow[b]{2}{*}{$\begin{array}{l}\text { Aylar } \\
\text { Months }\end{array}$} & \multicolumn{4}{|c|}{$\begin{array}{l}\text { Sicaklik }\left({ }^{\circ} \mathrm{C}\right) \\
\text { Temperature }\end{array}$} & \multicolumn{2}{|c|}{$\begin{array}{l}\text { Nispi nem (\%) } \\
\text { Relative humidity }\end{array}$} & \multicolumn{2}{|c|}{$\begin{array}{l}\text { Yağış }\left(\mathrm{mm}=\mathrm{kg} / \mathrm{m}^{2}\right) \\
\text { Total rainfall }\end{array}$} \\
\hline & $\begin{array}{l}2015 \\
\text { Min. }\end{array}$ & $\begin{array}{l}2015 \\
\text { Max. }\end{array}$ & $\begin{array}{l}2015 \\
\text { ort. } \\
\text { Ave. }\end{array}$ & $\begin{array}{c}\text { Uzun } \\
\text { y1llar ort. } \\
\text { Long years } \\
\text { ave. }\end{array}$ & 2015 & $\begin{array}{c}\text { Uzun yillar } \\
\text { ort. } \\
\text { Long years } \\
\text { ave. }\end{array}$ & 2015 & $\begin{array}{c}\text { Uzun yillar ort. Long } \\
\text { years ave. }\end{array}$ \\
\hline Ocak & $-17,0$ & 11,5 & $-1,5$ & $-0,6$ & 88,1 & 79,0 & 28,6 & 29,4 \\
\hline Şubat & $-11,4$ & 16,0 & 2,0 & 1,1 & 77,5 & 73,3 & 21,4 & 28,1 \\
\hline Mart & $-6,2$ & 21,9 & 5,1 & 4,8 & 76,4 & 69,1 & 34,0 & 38,5 \\
\hline Nisan & $-4,4$ & 24,7 & 7,6 & 9,5 & 62,5 & 66,3 & 31,6 & 50,5 \\
\hline Mayıs & 1,7 & 32,5 & 14,9 & 14,2 & 67,1 & 68,0 & 63,8 & 77,9 \\
\hline Haziran & 9,1 & 27,7 & 16,9 & 17,7 & 78,7 & 67,4 & 154,9 & 89,6 \\
\hline Temmuz & 9,4 & 35,9 & 20,4 & 20,5 & 62,6 & 61,9 & 16,8 & 36,0 \\
\hline Ağustos & 6,6 & 34,0 & 20,9 & 20,5 & 64,5 & 61,8 & 41,9 & 38,2 \\
\hline Eylül & 7,4 & 35,6 & 18,9 & 16,2 & 68,0 & 66,7 & 51,8 & 38,7 \\
\hline Ekim & 2,2 & 23,3 & 12,1 & 11,2 & 83,6 & 73,8 & 94,7 & 34,8 \\
\hline Kasım & $-3,6$ & 19,9 & 6,1 & 4,9 & 81,1 & 78,0 & 31,8 & 27,5 \\
\hline Aralık & $-10,2$ & 10,2 & $-0,9$ & 0,7 & 87,1 & 82,1 & 25,6 & 36,1 \\
\hline Ortalama & & & 0,21 & 10,05 & 74,77 & 70,62 & 49,74 & 43,77 \\
\hline
\end{tabular}

Kaynak: Meteorolojik veri arşiv ve yönetim sistemi. Meteoroloji 10. Bölge Müdürlüğü Kastamonu/17074 no'lu istasyonu. Source: Meteorological data archive and management system. Station of the $10^{\text {th }}$ Regional Directorate of Meteorology, Kastamonu/17074. 


\section{BULGULAR ve TARTIŞMA}

Genotiplere ait yerel isimler, lokasyon bilgileri (il, ilçe, köy, rakım), ağaç yaşı, çiçeklenme ve hasat tarihleri ile periyodisite durumları Çizelge 3 'te yer almaktadır. Erfelek ilçesinde 133-676 m, Kastamonu Merkez ilçesinde 725-846 m rakımlarda söz konusu genotiplerin yetiştiği tespit edilmiştir. Çiçeklenme, Nisan ayının 1. yarısında (Ağustos, Sarı ömer ve Yaz elması), 10-20 Nisan (Kabak, Kaba tatlı, Yeşil, İskilip, Hüryemez 2, Sisli Hüryemez ve S1k1 misket elmas1), 20-30 Nisan tarihleri (Kaba, Miskin ve Hüryemez 1 elması) çiçeklenenler ve 5-15 Mayıs tarihleri arasında çiçeklenler (Demir elması) olmak üzere 4 dönem belirlenmiştir. Çiçeklenmenin en yoğun olduğu dönem 10-20 Nisan dönemi olarak belirlenmiştir. Hasat zamanı, bakımından da 4 dönem belirlenmiş olup bunlar Temmuz sonu (Yaz elmas1), Ağustos sonu- Eylül başı (Ağustos, Sarı̈mer ve Yeşil elma), Eylül sonu-Ekim başı (Kabak, Kaba, Kaba tatlı, Miskin, Hüryemez 1, İskilip, Hüryemez 2, Sisli Hüryemez ve S1k1 misket elması) ve Ekim sonu (Demir elması) olarak sıralanmaktadır.

Elma genotiplerinin çiçeklenme tarihi Yarılgaç ve ark. (2009), Ordu merkez ilçesinde yetiştirilen elma genotipleri, Aygün ve Ülgen (2009), Rize ilinde demir elması genotipleri ve Balta ve ark. (2015), Ordu ili Kumru ilçesinde yetiştirilen elma genotipleri ile yapmış oldukları çalışmalardan elde etmiş oldukları sonuçlar ile uyum içerisindedir. Genotiplerin çoğunluğunun Eylül sonu-Ekim baş1 (Çizelge 3) dönemde olgunlaştığ 1 dikkat çekmektedir. Genotiplerin hasat tarihi Uzun ve ark. (2015), Çamaş (Ordu) yöresinde yetişen yerel elma genotipleri, Kirkaya ve ark. (2014), Perşembe (Ordu) yöresinde yetiştirilen elma genotipleri ve Macit ve ark. (2021), Artvin ilinde yetiştirilen elma genotipleri ile yapmış oldukları çalışmalardan elde etmiş oldukları sonuçlar ile benzerlik göstermektedir. Ayrıca üretici anketleri sonucunda 14 yerel çeşidin 9 adedinde periyodisite eğilimi olmadığı anlaşılmaktadır. Bolat (1991), Konya Yöresinde incelemiş olduğu elma genotiplerinden 10 tanesinde periyodisite gözlemlemiş, 2 tanesinde k1smen periyodisite olduğunu bildirmiştir. Van Yöresi'nden seçilen 11 elma genotipinde periyodisite eğilimi gözlenmemiştir (Kaya ve Balta 2009). Uygun bakım koşulları altında bu genotiplerin periyodisiteye eğilim durumlarının değişebileceği ve bu genotipler üzerinde detaylı araştırmalara devam edilmesi gereklidir sürdürülmesi önerilmektedir

Çizelge 3. Elma genotiplerinin isim, yer, rakım, ağaç yaşı, fenoloji, alternans eğilim bilgileri.

Table 3. Name, location, altitude, tree age, phenology, alternans trend information of apple genotypes.

\begin{tabular}{|c|c|c|c|c|c|c|c|c|}
\hline $\begin{array}{c}\text { Genotip ad1 } \\
\text { Genoype name }\end{array}$ & A. İl & A. İlçe & A. Köy & Rakım & AY & ÇT & HT & PD \\
\hline Kabak Elma & Sinop & Erfelek & Başaran Köyü & 133 & 20 & 10-20 Nisan & 20-30 Eylül & Yok \\
\hline Kaba Elma & Sinop & Erfelek & Başaran Köyü & 133 & 60 & 20-30 Nisan & 25 Eylül-10 Ekim & Yok \\
\hline Kaba Tatlı & Sinop & Erfelek & İnesekü Köyü & 676 & 40 & 10-20 Nisan & 20-30 Eylül & Var \\
\hline Ağustos Elması & Sinop & Erfelek & İnesekü Köyü & 290 & 15 & 5-15 Nisan & 20-30 Ağustos & Var \\
\hline Yeşil Elma & Sinop & Erfelek & İnesekü Köyü & 290 & 15 & 10-20 Nisan & 1-10 Eylül & Var \\
\hline Miskin Elma & Sinop & Erfelek & İnesekü Köyü & 317 & 20 & 20-30 Nisan & 1-15 Ekim & Var \\
\hline Hüryemez 1 & Sinop & Erfelek & İnesekü Köyü & 317 & 40 & 20-30 Nisan & 1-15 Ekim & Yok \\
\hline İskilip Elması & Sinop & Erfelek & İnesekü Köyü & 317 & 15 & 10-20 Nisan & 20-30 Eylül & Var \\
\hline Hüryemez 2 & Kastamonu & Merkez & Dokuzkat köyü & 725 & 20 & 10-20 Nisan & 20-30 Eylül & Yok \\
\hline Sisli Hüryemez & Kastamonu & Merkez & Dokuzkat Köyü & 756 & 15 & 10-20 Nisan & 20-30 Eylül & Yok \\
\hline Sik1 Misket & Kastamonu & Merkez & Göçen Köyü & 840 & 15 & 10-20 Nisan & 20-30 Eylül & Yok \\
\hline Sarı̈̈mer Elmas1 & Kastamonu & Merkez & Göçen Köyü & 846 & 20 & 5-15 Nisan & 20-30 Ağustos & Yok \\
\hline Demir Elması & Kastamonu & Merkez & Göçen Köyü & 743 & 25 & 5-15 Mayis & 20-30 Ekim & Yok \\
\hline Yaz Elmas1 & Kastamonu & Merkez & Göçen Köyü & 761 & 20 & 1-10 Nisan & 20-30 Temmuz & Yok \\
\hline
\end{tabular}

A.il: Alındığı il (province of origin), A. İlçe: Alındığı ilçe (district of purchase), A. köy: Alındığı köy (purchased village), AY: Ağaç yaşı (tree age), ÇT: Çiçeklenme tarihi (flowering date), HT: Hasat tarihi (harvest date), PD: Periyodisite durumu (periodicity status). 
Calıșma materyalini oluşturan genotiplerin meyve özellikleri Çizelge 4'te verilmiştir. Buna göre, ortalama meyve ağırlıkları 59,3-220,8 g sınırlarında değişim göstermiştir. $\mathrm{Bu}$ değer, bu konuda bölgeden elde edilen diğer araștırma bulguları ile benzerlik göstermektedir. Bostan (2009), Trabzon ilindeki yerel elma genotipleri ile yapmış olduğu çalışmada meyve ağırlığının 60,84 242,24 g arasında değiştiğini tespit etmiştir. Bostan ve Acar (2009), Ünye Yöresi elma genotiplerinin meyve ağırlı̆̆ının 59,79-273,41g olduğunu belirtmişlerdir. Gürel (2010), Ordu Merkez ilçede yetişen elma genotiplerinin meyve ağırlığının 89,51-278,76 g olarak belirlemişlerdir. Çalışmadan elde edilen sonuçlar ile yapılmış olan çalışmalardan elde edilen sonuçlar uyum içerisindedir. Genotiplerin meyve boyu 48,3-67,3 $\mathrm{mm}$, meyve eni 50,4-85,0 $\mathrm{mm}$ ve meyve şekil indeksi için 0.77-1.01 arasında bulunmuştur. Buna göre, meyve şeklinin 'yeşil elma' hariç basık olduğu ortaya çıkmıştır. Karadeniz ve ark. (2013), meyve boyu 53,14-62,07 mm, meyve eni 63,46$73,79 \mathrm{~mm}$ meyve şekil indeksini ise 0,79-0,86; Gümüşhane ili merkez ilçede yapılan çalışmada meyve boyu 52,09-66,29 mm, meyve eni 57,27-
$80,77 \mathrm{~mm}$ ve meyve şekil indeksini ise $0,77-0,92$ (Şenyurt ve ark., 2015); Artvin ilinde yerel elma genotipleri ile yapılan bir diğer çalışmada meyve boyu 20,19-78,72 $\mathrm{mm}$ meyve eni ise 18,69-92,22 mm (Macit ve ark., 2021) olarak belirlemişlerdir. Elde edilen bulgular diğer çalışmalar ile uyum içinde olduğu görülmektedir. Türk Standartları Enstitüsü, ekstra sınıfa girecek meyvelerin $65 \mathrm{~mm}$ ve daha üstünde çapa sahip olmaları gerektiğini bildirmiştir. $\mathrm{Bu}$ sinıflandırmaya göre Kabak, Ağustos, Hüryemez 1, Hüryemez 2, Sisli Hüryemez, Sar1 ömer, Demir ve Yaz elmasının meyveleri ekstra sinifina girmektedir. Genotiplerin meyve sap uzunluğu 7,9-17,5 $\mathrm{mm}$, meyve sap kalınlığ 1 ise $1,7-3,7 \mathrm{~mm}$ arasında değiştiği belirlenmiştir. Benzer çalışmalarda meyve sap uzunluğu ve meyve sap kalınlığını sirasıyla 8,13$18,99 \mathrm{~mm}, 2,38-6,14 \mathrm{~mm}$ (Yarılgaç ve ark., 2009); 8,41-11,59 mm, 2,37-3,40 mm (Karadeniz ve ark., 2013); 10,99-21,47 mm, 2,24-4,52 mm (Balta ve ark., 2015) arasında olduğunu bildirmişlerdir. Elde ettiğimiz sonuçlar ile daha önce yapılan çalışmalardan elde edilen sonuçlar arasında uygunluk görülmektedir.

Çizelge 4. Elma genotiplerinin meyve özellikleri.

Table 4. Fruit characteristics of apple genotypes.

\begin{tabular}{|c|c|c|c|c|c|c|c|c|}
\hline $\begin{array}{l}\text { Genotip ad } 1 \\
\text { Genotype name }\end{array}$ & $\begin{array}{l}\text { MA } \\
(\mathrm{g})\end{array}$ & $\begin{array}{c}\mathrm{MB} \\
(\mathrm{mm})\end{array}$ & $\begin{array}{c}\mathrm{ME} \\
(\mathrm{mm})\end{array}$ & MŞİ & $\begin{array}{l}\mathrm{MSU} \\
(\mathrm{mm})\end{array}$ & $\begin{array}{l}\text { MSK } \\
(\mathrm{mm})\end{array}$ & $\begin{array}{c}\text { SÇKM } \\
(\%)\end{array}$ & $\begin{array}{l}\text { TEA } \\
(\%)\end{array}$ \\
\hline Kabak Elma & $165,0 \pm 1,8$ & $64,2 \pm 3,0$ & $79,5 \pm 2,1$ & $0,81 \pm 2,6$ & $10,3 \pm 2,2$ & $3,3 \pm 1,3$ & $12,8 \pm 0,1$ & $0,55 \pm 0,03$ \\
\hline Kaba Elma & $85,3 \pm 1,1$ & $56,3 \pm 1,6$ & $58,9 \pm 2,9$ & $0,96 \pm 2,1$ & $8,3 \pm 2,5$ & $3,1 \pm 0,8$ & $14,4 \pm 0,2$ & $0,41 \pm 0,01$ \\
\hline Kaba Tatlı & $112,5 \pm 1,7$ & $57,1 \pm 1,5$ & $64,7 \pm 1,7$ & $0,88 \pm 1,6$ & $9,9 \pm 1,3$ & $3,0 \pm 1,1$ & $13,2 \pm 0,2$ & $0,51 \pm 0,01$ \\
\hline Ağustos Elmas1 & $135,7 \pm 3,3$ & $55,0 \pm 1,3$ & $70,0 \pm 1,8$ & $0,79 \pm 1,3$ & $15,1 \pm 2,2$ & $3,7 \pm 1,2$ & $12,6 \pm 0,3$ & $0,53 \pm 0,02$ \\
\hline Yeşil Elma & $102,9 \pm 5,2$ & $62,9 \pm 2,4$ & $62,4 \pm 2,3$ & $1,01 \pm 2,1$ & $10,9 \pm 2,5$ & $3,4 \pm 1,1$ & $12,0 \pm 0,2$ & $0,60 \pm 0,02$ \\
\hline Miskin Elma & $73,2 \pm 2,8$ & $50,9 \pm 0,7$ & $56,4 \pm 0,9$ & $0,90 \pm 0,7$ & $14,2 \pm 3,3$ & $3,2 \pm 0,7$ & $14,4 \pm 0,2$ & $0,41 \pm 0,01$ \\
\hline Hüryemez 1 & $220,8 \pm 5,2$ & $67,3 \pm 0,3$ & $82,0 \pm 1,8$ & $0,82 \pm 0,9$ & $7,9 \pm 1,1$ & $2,4 \pm 1,0$ & $13,4 \pm 0,2$ & $0,51 \pm 0,02$ \\
\hline İskilip Elmas1 & $59,3 \pm 4,5$ & $48,3 \pm 1,6$ & $50,4 \pm 2,6$ & $0,96 \pm 1,8$ & $14,5 \pm 3,1$ & $2,1 \pm 0,9$ & $15,6 \pm 0,4$ & $0,50 \pm 0,02$ \\
\hline Hüryemez 2 & $158,2 \pm 3,1$ & $65,2 \pm 1,8$ & $73,2 \pm 1,0$ & $0,89 \pm 1,3$ & $16,5 \pm 1,1$ & $1,8 \pm 1,0$ & $13,6 \pm 0,1$ & $0,45 \pm 0,01$ \\
\hline Sisli Hüryemez & $217,4 \pm 6,4$ & $65,8 \pm 1,1$ & $85,0 \pm 1,9$ & $0,77 \pm 1,5$ & $13,7 \pm 2,2$ & $2,3 \pm 1,1$ & $16,2 \pm 0,1$ & $0,26 \pm 0,02$ \\
\hline S1k1 Misket & $82,0 \pm 4,5$ & $49,1 \pm 1,7$ & $54,1 \pm 0,5$ & $0,91 \pm 1,6$ & $17,5 \pm 2,1$ & $1,7 \pm 0,9$ & $13,6 \pm 0,4$ & $0,40 \pm 0,01$ \\
\hline Sarı̈̈mer Elması & $118,1 \pm 2,1$ & $62,8 \pm 1,3$ & $68,3 \pm 2,7$ & $0,92 \pm 2,0$ & $13,0 \pm 1,6$ & $2,6 \pm 1,1$ & $15,4 \pm 0,2$ & $0,35 \pm 0,02$ \\
\hline Demir Elmas1 & $124,1 \pm 2,7$ & $56,4 \pm 1,7$ & $70,1 \pm 1,4$ & $0,80 \pm 1,6$ & $15,5 \pm 2,3$ & $1,7 \pm 0,9$ & $16,0 \pm 0,3$ & $0,25 \pm 0,01$ \\
\hline Yaz Elmas1 & $135,1 \pm 1,0$ & $57,4 \pm 1,3$ & $71,9 \pm 1,4$ & $0,80 \pm 1,2$ & $8,8 \pm 2,1$ & $2,4 \pm 1,0$ & $13,2 \pm 0,3$ & $0,53 \pm 0,02$ \\
\hline
\end{tabular}

MA: Meyve ağırlığı (fruit weight), MB: Meyve boyu: (fruit length), ME: Meyve eni (fruit width), MŞİ: Meyve şekil indeksi (fruit shape index), MSU: Meyve sap uzunluğu (fruit stalk length), MSK: Meyve sap kalınlığı (fruit stalk thickness), SÇKM: Suda çözünebilir kuru madde (water soluble dry matter). TEA: Titre edilebilir asitlik (Titratable acidity). 
Elmada SÇKM, asit ve aroma bileşikleri yeme kalitesini belirlemektedir. İncelenen genotiplerde SÇKM içeriği $\% 12,0$ ile $\% \quad 16,20$ arasında değişmiştir (Çizelge 4). Bu değeri Karlıdağ ve Eşitken (2006) \% 9,10-13,80; Fischer ve Fischer (2002) \% 13,0-15,4; Bostan ve Acar (2009) \% 9,50-13,50; Yarılgaç ve ark. (2009) \% 10,6213,85; Doğru (2012) \% 10,65-15,00; Karadeniz ve ark. (2013) \% 11,63-12,80 arasinda bildirmektedirler. Elde edilen veriler diğer araştırma verileriyle benzerlik göstermektedir Öte yandan çalışmamızda elma genotiplerinde titre edilebilir asitlik \%0,25-0,60 bulunmuștur. $\mathrm{Bu}$ değer, Pink lady \%0,7-0,9 olarak bildirilirken (Cripps ve ark. 1993), bölgede yapılan diğer çalışmalarla da (Osmanoğlu, 2008; Doğru, 2012; Karadeniz ve ark., 2013; Balta ve ark., 2015; Şenyurt ve ark., 2015; Macit ve ark., 2021) uyumlu olduğu görülmüştür.

\section{LITERATÜR LISSTESI}

Aygün, A. ve S.A. Ülgen. 2009. Rize'de yetiştirilen demir elma (Malus communis L.) çeşidinin bazı meyve özelliklerinin belirlenmesi. TABAD Tarım Bilimleri Araştırma Dergisi 2 (2): 201-205.

Balta M. F., T. Kaya, H. Kırkaya ve O. Karakaya. 2015. Kumru (Ordu) yöresinde yetiştirilen mahalli elma genotiplerinin fenolojik, morfolojik ve pomolojik özellikleri. Gaziosmanpaşa Üniversitesi Ziraat Fakültesi Dergisi. 32: 47-56.

Bolat, S. 1991. Konya İlinde Kaliteli Yazlık Elma Tiplerinin Seleksiyon Yoluyla Islahı Üzerine Bir Araştırma (doktora tezi, basılmamış). Atatürk Ünv. Fen Bilimleri Enst, Erzurum.

Bostan, Z. 2009. Pomological traits of local apple and pear cultivars and types grown in Trabzon province (Eastern Black Sea Region of Turkey). Acta Hort., 825: 293-298.

Bostan, S. Z. ve Ş. Acar. 2009. Ünye (Ordu) ve çevresinde yetiştirilen mahalli elma çeşitlerinin pomolojik özellikleri. TABAD Tarım Bilimleri Araştırma Dergisi 2(2): 15-24.

Bostan, S. Z. and E. Y1lmaz. 2015. Breeding by selection of 'Yomra' and 'Demir' apple varieties (Malus communis L.) grown in Arsin and Yomra districts (Trabzon Province, Turkey). Meyve Bilimi 2: 60-69.

\section{SONUÇ ve ÖNERILER}

Sinop ve Kastamonu illerindeki yerel elma genotiplerinin bazı meyve özelliklerinin belirlendiği bu çalışmada meyve ağırlığı ve meyve boyu bakımından Hüryemez 1 genotipi, meyve eni ve suda çözünebilir kuru madde miktarı bakımından ise Sisli Hüryemez genotipi ilk sırada yer almıştır. $\mathrm{Bu}$ genotipler geçmişten günümüze kadar bölgede birçok ticari çeşit olmasına rağmen günümüze kadar gelmişlerdir. $\mathrm{Bu}$ durum bu genotiplerin meyve tadı, aroması, bazı hastalık ve zararlılara karşı direnç gibi bazı üstün yanları olduğunu göstermektedir. $\mathrm{Bu}$ ve benzer özellikler bu genotiplerin 1slah yöntemleri ile geliştirilebilecek üstün özelliklere sahip çeşit adayı olma potansiyelleri olduğunu göstermektedir. Bu nedenle bu genotiplerin daha kapsamlı islah çalışmaları ile değerlendirilmesi gerekmektedir.

Cripps, S. E. L., L.A. Richards, and A. M. Mairata. 1993. "Pink Lady" Apple. HortScience 28(10): 1057.

Çalışkan, O., S. Bayazit, M. Oktem and A. Ergul. 2017. Evaluation of the genetic diversity of pomegranate accessions from Turkey using new microsatellite markers. Turk. J. Agric. For., 41, 142-153. 8.

Doğru, B. 2012. Çorum ili İskilip ilçesinde yetiştirilen mahalli misket elmalarının fenolojik, morfolojik, pomolojik özelliklerinin belirlenmesi ve moleküler olarak tanımlanması. Yüksek Lisans Tezi. Ordu Ünv. Fen Bil. Enstitüsü. Ordu, 122 s.

Dumanoğlu, H., A. Aygün, V. Erdoğan, Ü. Serdar, Ö. Kalkışım, K. Baştaş, M. A. Pakyürek ve S. Maden. 2011. Doğu Karadeniz Bölgesi sahil kuşağındaki bazı yerel elma çeșitlerinin meyve özellikleri bakımından değerlendirilmesi. VI. Ulusal Bahçe Bitkileri Kongresi. 04-08 Ekim 2011. Cilt 1, s. 173-180, Şanlıurfa.

Engin, S.P. and C. Mert. 2020. The effects of harvesting time on the physicochemical components of aronia berry. Turk. J. Agric. For., 44, 361-370.

Fischer, M., Fischer, C., 2002. Pinova Apple Cultivar. The Compact Fruit Tree, 35 (1): 19-20.

Gürel, H. B. 2010. Ordu Merkez ilçede yetişen elma (Malus communis L.) tiplerinin fenolojik, pomolojik ve 
morfolojik özellikleri. O.Ü, Fen Bilimleri Enstitüsü. Yayınlanmamış Yüksek Lisans Tezi. Ordu.

İslam, A., Z. Bostan ve E. Y1lmaz. 2009. Trabzon ili Yomra ilçesinde yetişen yomra elmasının pomolojik özellikleri üzerine bir araştırma. TABAD Tarım Bilimleri Araştırma Dergisi 2(2): 107-110.

Kaplan, N. ve İ. Macit. 2009. Samsun Koşullarında Bazı Elma Çeşitlerinin Bitkisel Gelişimi ve Verimliliği Üzerine Elma Klon Anaçların Etkisi. Tarım Bilimleri Araştırma Dergisi, 2(2): 159-166.

Karadeniz, T., E. T. Akdemir, İ. Y1lmaz ve H. Aydın. 2013. Piraziz elmasinda klon seleksiyonu. Akademik Ziraat Dergisi, 2: 17-22.

Karakaya, O., M. F. Balta, T. Kaya ve S. Uzun. 2015. Yağlıdere (Giresun) elmaları: fenolojik ve pomolojik özellikler. VII. Ulusal Bahçe Bitkileri Kongresi. 25-29 Ağustos 2015. Bahçe Özel Sayı-VII. Ulusal Bahçe Bitkileri Kongresi Bildirileri, Cilt 1, s. 925-929, Çanakkale.

Karatas, N. and M. Sengul. 2020. Some important physicochemical and bioactive characteristics of the main apricot cultivars from Turkey. Turk. J. Agric. For., 44, 651-661.

Karlıdağ, H. ve A. Eşitken. 2006. Yukarı çoruh vadisinde yetiștirilen elma ve armut çeșitlerinin bazı pomolojik özelliklerinin belirlenmesi. Yüzüncü Y1l Üni. Zir. Fak. Tarım Bilimleri Dergisi (J.Agric. Sci.), 16(2): 93-96.

Kaya. T. ve Balta, F. 2009. Van Yöresi elma seleksiyonları 1: Peryodisite göstermeyen genotipler. Tarım Bilimleri Araştırma Dergisi, 2: 25-30.

Kaya, T. and F. Balta. 2013. Apple selection in Van province. J. Agric. Sci. 2, 91-98.

Kırkaya, H., M. F. Balta ve T. Kaya. 2014. Perșembe (Ordu/Türkiye) yöresinde yetiştirilen elma genotiplerinin pomolojik, morfolojik ve fenolojik özellikleri. Iğdır Üni. Fen Bilimleri Enst. Der. 4: 15- 20.
Macit, İ., E. Aydın, A. Tas and M. Gundogdu. 2021. Fruit quality properties of the local apple varieties of Anatolia. Sustainability, 13(11), 6127.

Osmanoğlu, A. 2008. Posof (Ardahan) yöresi genetik kaynaklarının enolojik, morfolojik, pomolojik ve moleküler tanımlanması. Doktora Tezi. Yüzüncü Yıl Ünv. Fen Bil. Enstitüsü. Van, 179 s.

Özbek, S. 1978. Özel Meyvecilik. Ç. Ü. Ziraat Fakültesi Yayınları:128, Ders Kitab1; 11, 486 s, Adana.

Serdar, Ü., B. Ersoy, A. Öztürk ve H. Demirsoy. 2007. Saklı cennet Camili'de yetiştirilen yerel elma çeşitleri. V. Ulusal Bahçe Bitkileri Kongresi Bildiriler Kitab1 1: 575-579.

Şehirali, S. ve M. Özgen. 1987. "Bitkisel Gen Kaynakları" ders kitabı, A.Ü. Ziraat Fakültesi Yayınları, No: 1020, Ders kitabı No: 294, A. Ü. Basımevi.

Şenyurt, M., Ö. Kalkışım ve T. Karadeniz. 2015. Gümüşhane yöresinde yetiştirilen bazı standart ve mahalli elma (Malus communis L.) çeşitlerinin pomolojik özellikleri. Akademik Ziraat Dergisi 4(2):59-64.

Uzun, S., M. F. Balta, T. Kaya ve O. Karakaya. 2015. Çamaş (Ordu) yöresinde yetişen yerel elma genotiplerinin fenolojik ve pomolojik özellikleri. VII. Ulusal Bahçe Bitkileri Kongresi. 25-29 Ağustos 2015. Bahçe Özel Say1-VII. Ulusal Bahçe Bitkileri Kongresi Bildirileri, Cilt 1, s. 653-657, Çanakkale.

Yarılgaç, T., T. Karadeniz. ve H. B. Gürel. 2009. Ordu merkez ilçede yetiştirilen yöresel elma (Malus communis L.) çeşitlerinin fenolojik ve pomolojik özelliklerinin belirlenmesi. TABAD Tarım Bilimleri Araştırma Dergisi 2(2): 37-41. 